\title{
An Exploration Of The Effectiveness Of An Audit Simulation Tool In A Classroom Setting
}

Robert C. Zelin II, Minnesota State University, Mankato, USA

\begin{abstract}
The purpose of this study was to examine the effectiveness of using an audit simulation product in a classroom setting. Many students and professionals feel that a disconnect exists between learning auditing in the classroom and practicing auditing in the workplace. It was hoped that the introduction of an audit simulation tool would help to ameliorate the perceived disconnect. The simulation product selected was Real Audit. Over the course of eight weeks, 22 students enrolled in an Assurance Services class completed five major audit simulation modules: Planning, Accounts Receivable, Accounts Payable, Fixed Assets and Inventory. At the end of the project, students were asked to evaluate the simulation experience. Most students felt that the experience was interesting and helpful in terms of understanding the tasks that an auditor performs. While the majority of students recommended that the simulation should be used in future classes, concerns were expressed about the amount of time that the project consumed.
\end{abstract}

\section{INTRODUCTION}

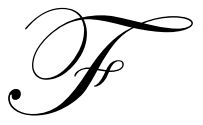

or many years, active learning has been an important component in the development of course curriculum for some instructors. As the name implies, active learning involves "learning by doing." Students are often engaged in an activity that requires them to solve a problem either individually or in groups. Simulations are often a component of active learning. Drew, 1968, defined simulations as dynamic representations of a real world component that utilize a computer model and involve the movement through time (Drew, 1968). Simulations can be used in a school or university setting or can be used in an industrial or company setting. Simulations can be used in a synchronous or asynchronous learning environment. Additionally simulations can be computer-based, laboratory-based or paper and pencil-based.

\section{SIMULATIONS AS LEARNING TOOLS}

The use of simulations as an active learning tool can start very early in the educational process. Arner, 1998, stated that students in the second grade can participate in a simulation called "Zoo" where they become members of a community that is trying to save a local zoo. The author also mentioned simulations where students in grades 4 through 8 explore pioneer life, oceans, machines, insects and space. Arner felt that the active and participatory nature of simulations aided the students in their knowledge retention (Arner, 1998).

In higher education simulations have been utilized in a vast and diverse number of disciplines such as, physics (Dori \& Belcher, 2005), supply change management (Zeng \& Johnson, 2009), economics (Porter, Riley, \& Ruffer, 2004), higher education administration (Prisk \& Dunn, 2002), public health (Spinello \& Fischbach, 2008), and civil engineering (Chen \& Levinson, 2006). Dori and Belcher, 2005, developed the Technology Enabled Active Learning (TEAL) Project at MIT. The project was a conglomeration of short lectures, recitations and simulation experiences. The objectives of the TEAL Project were six fold: "Transform the way physics is taught at large enrollment physics classes at MIT; Decrease failure rates in these courses; Create an engaging and technologically enabled active learning environment; Move away from a passive lecture/recitation format; Increase students' conceptual and analytical understanding of the nature and dynamics of electromagnetic fields and phenomena; and 
Foster students' visualization skills." (Dori and Belcher, 2005, page 253) The authors utilized an experimental group/control group research format and instituted a pre-test/post-test paradigm. The authors found that the experimental group exhibited greater relative improvement between pre-test and post-test scores when contrasted with the control group. The students were asked if they would recommend the TEAL-based class to other students. In one experimental section of 179 students, seventy percent responded "yes." Whereas, in another experimental section of 514 students, only 54 percent responded "yes." (Dori \& Belcher, 2005)

Zeng and Johnson, 2009, also utilized an experimental group/control group research format. Their study involved the use of a discovery-based laboratory simulation in a supply chain management situation. The authors found that students who participated in the discovery-based laboratory performed better on evaluation measures than did their counterparts who had not been exposed to the discovery-based laboratory. Student feedback about the laboratory was found to be very positive. (Zeng \& Johnson, 2009)

Chen and Levinson, 2006, conducted a study using a computer-based growth simulation program called Simulator of Network Growth (SONG) in a civil engineering course, Transportation Systems Analysis, at the University of Minnesota. The experimenter randomly divided students enrolled in the course into two groups. One group was required to complete a traditional case study assignment (control group) and the other group was required to complete a SONG-based assignment (treatment group). The authors hypothesized that treatment group would outperform the control group on a variety of measures that were generated by students' responses to a preassignment and postassignment survey and students' grades on a final examination. The analysis of data from the preassignment and postassignment surveys indicated that the treatment group's perceived understanding of network patterns was greater than that of the control group. The treatment group also exhibited significant perceived skill improvement levels when compared to the perceived levels of the control group. When the final examinations for the two groups were analyzed, the authors found no difference between the two groups on subject comprehension but they did find that the treatment group performed significantly better in the area of problem solving skills. (Chen \& Levinson, 2006)

Spinello and Fischbach, 2008, examined the effectiveness of a traditional problem-based learning experience versus a problem-based learning experience using a computer simulation. Scores on a final essay examination were compared for both groups. The group with the computer simulation experience outperformed the traditional group. (Spinello \& Fischbach, 2008)

\section{SIMULATIONS AS SURROGATES}

Vescoukis et. al., 2003, stated that simulations can serve as a surrogate for on-the-job training. Oftentimes, as a practical matter, it is difficult to schedule on-the-job training or internships for students. The training or internship does not fit into the student's schedule. The authors also mention the legal responsibility that companies assume with on-the-job training or internships. Thus, simulations often become a good alternative for students. (Vescoukis, Retalis, \& Anagnostopoulos, 2003)

\section{SIMULATIONS IN BUSINESS}

Most simulations in business involve a student or a group of students who are asked to make decisions about a fictional company over several time periods. All participants start with the same company information. During each reporting period, they are asked to make a series of strategic decisions, such as the marketing dollars that should be spent in various territories or the projected production for a certain product. After the decisions have been entered into the simulation program, participants are provided with financial and factual results. From the output provided, the participants then are asked to make another series of strategic decisions. The decision-result cycle is repeated for a specified number of periods. At the end of the simulation, each constituent will end up with a company that has succeeded, regressed or failed even though each constituent started with the same facts.

Several authors have advocated the use of audit software, audit simulations or cases in Auditing and Assurance Services classes (Weidenmier \& Herron, 2004), (Nieschwietz, Pany, \& Zhang, 2002) and (Gelinas, Schwarzkopf, \& Tibodeau, 2008) One such product is Real Audit which is an interactive simulation of the financial 
statement auditing environment. The simulation was developed by John Schatzel. In 2008 the author received the Innovation in Accounting Education Award from the American Accounting Association for the development of the software. Within the simulation participants are asked to assume the role of an in-charge accountant on an audit engagement. The participant has two inexperienced staff accountants at her or his disposal. The in-charge accountant/participant is supervised by the audit manager and ultimately by the audit partner. At the company being audited, the in-charge accountant/participant may interact with eleven different characters. The in-charge accountant/participant is trying to determine if the financial statements of the company fairly represent the financial condition of the company. (Schatzel, Real Audit Users Manual, 2008) In order to make this determination, the individual must perform various audit functions in five major areas: Planning, Accounts Receivable, Fixed Assets, Accounts Payable and Inventory. The author of the simulation has prepared an instructor's guide with the approximate time to complete each module, the subcomponents of each module and the difficulty of each subcomponent. The information can be found in Table 1 (Schatzel, Real Audit Instructor's Manual, 2008).

Table 1- Audit Modules

\begin{tabular}{|c|c|c|c|}
\hline Module & Time (Hrs) & Subcomponents & Difficulty \\
\hline \multirow[t]{7}{*}{ Client Acceptance and Engagement Planning } & \multirow[t]{7}{*}{1.5 to 4.25} & Engagement Risk & $\mathrm{M}$ \\
\hline & & Analytical Procedures & $\mathrm{M}$ \\
\hline & & Materiality & $\mathrm{M}$ \\
\hline & & Detection Risk & $\mathrm{M}$ \\
\hline & & Internal Control & $\mathrm{M}$ \\
\hline & & Risk of Material Misstatement & M \\
\hline & & Audit Strategy & $\mathrm{M}$ \\
\hline \multirow[t]{4}{*}{ Accounts Receivable } & \multirow[t]{4}{*}{.75 to 2} & Clerical & $\mathrm{E}$ \\
\hline & & Confirmations & M \\
\hline & & Sales Cutoff & $\mathrm{M}$ \\
\hline & & Valuation & $\mathrm{D}$ \\
\hline \multirow[t]{7}{*}{ Fixed Assets } & \multirow[t]{7}{*}{1 to 2} & Clerical & $\mathrm{E}$ \\
\hline & & Additions & $\mathrm{M}$ \\
\hline & & Retirements & $\mathrm{M}$ \\
\hline & & Repairs and Maintenance & $\mathrm{E}$ \\
\hline & & Depreciation Valuation/Allocation & M \\
\hline & & Leases & $\mathrm{D}$ \\
\hline & & Disclosure & $\mathrm{M}$ \\
\hline \multirow[t]{4}{*}{ Accounts Payable } & \multirow[t]{4}{*}{.75 to 2} & Clerical & $\mathrm{E}$ \\
\hline & & Completeness of Statements and Confirmations & E to $\mathrm{M}$ \\
\hline & & Search for Unrecorded Liabilities & $\mathrm{M}$ \\
\hline & & Disclosure & $\mathrm{M}$ \\
\hline \multirow[t]{8}{*}{ Inventory } & \multirow[t]{8}{*}{1.5 to 3} & Analytical Procedures & M \\
\hline & & Observation and Related Memo & $\mathrm{M}$ \\
\hline & & Clerical & $\mathrm{E}$ to $\mathrm{M}$ \\
\hline & & Shipping and Receiving Cutoff & $\mathrm{E}$ \\
\hline & & Pricing Test & M \\
\hline & & Lower of Cost or Market & $\mathrm{M}$ \\
\hline & & Valuation & $\mathrm{D}$ \\
\hline & & Disclosure & $\mathrm{E}$ to $\mathrm{M}$ \\
\hline
\end{tabular}

The five major modules of the Real Audit simulation were completed over an eight week period online at the Real Audit web site by twenty two accounting majors at a medium-sized university in the Midwest who were enrolled in an upper level Auditing and Assurance Services course. The course is a senior level elective course designed mainly for students who are interested in a profession in public accounting. Upon completion of each module, the instructor was emailed a score from the Real Audit administrator. The score received was translated into points earned for the particular module. At the end of the simulation points were also assigned based on the promotion level that the in-charge accountant/participant had achieved. The promotion level was also assigned by 
the Real Audit administrator. The total possible points that could be earned in each module and in the promotion category can be found in Table 2 . The maximum number of points that could be earned in the class totaled 1000 . Thus, the simulation project represented $14.5 \%$ of a student's grade in the course.

Table 2- Points Assigned to Modules and Promotion

\begin{tabular}{|l|c|}
\hline \multicolumn{1}{|c|}{ Module } & Total Possible Points \\
\hline Planning & 25 \\
\hline Accounts Receivable & 25 \\
\hline Fixed Assets & 25 \\
\hline Accounts Payable & 25 \\
\hline Inventory & 25 \\
\hline Promotion Level Achieved & 20 \\
\hline
\end{tabular}

Upon completion of the five components of the simulation, the students were given the opportunity to respond to an anonymous survey about the simulation. Each student who completed the survey placed their name on a list and was subsequently awarded five extra credit points. Of the 22 students who completed the survey, thirteen $(59 \%)$ of the students were male and nine $(41 \%)$ were female. The average number of enrolled credit hours for the class was 14.23 with a range from nine to eighteen. The average number of credit hours completed for the class was 134 with a range from 90 to 169. The average self-reported Grade Point Average for the class was 3.527 with a range from 3.0 to 3.94 .

Excluding the demographic questions, the survey was composed of sixteen questions. Eight questions were of a Likert-type scale nature, three questions were of a rank order nature, three questions were of open-ended nature and the remaining two questions were of a single choice nature. The Likert-type questions utilized a seven point scale where a response of one indicated that the participant strongly disagreed and a response of seven indicated that the participant strongly agreed. The statements and resulting means can be found in Table 3 .

Table 3- Survey Statements

\begin{tabular}{|l|c|}
\hline \multicolumn{1}{|c|}{ Statement } & Mean Response \\
\hline I found this project interesting. & 4.45 \\
\hline The length of time to complete the project was reasonable. & 3.77 \\
\hline Completing this project helped me to better understand the types of activities that auditors do in their jobs. & 4.82 \\
\hline I enjoyed completing the project activities. & 3.75 \\
\hline Completing this project improved my auditing skills. & 4.27 \\
\hline I would recommend this type of project in future classes. & 4.66 \\
\hline I could have learned the same things from a lecture that I learned from doing this project. & 3.36 \\
\hline
\end{tabular}

The students did tend to find the project interesting. Half of the students, eleven, assigned a value of five to the statement regarding interest. The strongest response in terms of agreement was found for the question relating to whether the simulation aided the students in understanding types of activities that auditors perform. Less than twenty percent of the students responded with a value between one and three. While the responses to the effect of the simulation on audit skill improvement were not quite as favorable as the responses to the understanding of audit activities statement, they were still favorable. Overall the students felt that the simulation should be used in future classes.

When asked to rank order the five Real Audit modules in terms of being interesting, the students assigned the highest rankings to Planning and Accounts Receivable and the lowest rankings to Fixed Assets and Inventory. A summary of the rankings can be found in Table 4. A ranking of 1 represented the most interesting module and a ranking of 5 represented the least interesting module. 
Table 4- Ranking of Modules in Terms of Interest

\begin{tabular}{|l|c|c|c|c|c|}
\hline \multirow{2}{*}{ Module } & \multicolumn{5}{c|}{ Ranking } \\
\cline { 2 - 6 } & $\mathbf{1}$ & $\mathbf{2}$ & $\mathbf{3}$ & $\mathbf{4}$ & $\mathbf{5}$ \\
\hline Planning & 9 & 3 & 4 & 2 & 5 \\
\hline Accounts Receivable & 4 & 11 & 5 & 6 & 0 \\
\hline Accounts Payable & 3 & 4 & 6 & 8 & 3 \\
\hline Fixed Assets & 2 & 1 & 6 & 5 & 5 \\
\hline Inventory & 4 & 3 & 1 & & 9 \\
\hline
\end{tabular}

When the students were asked to rank order the Real Audit modules in terms of helping them to improve their audit skills, the students favored Planning, Accounts Receivable and Inventory. The students found Accounts Payable, Fixed Assets and Inventory to be least helpful. It is interesting to note that the Inventory module produced bimodal results. That is, it was the most helpful for some students and the least helpful for others. A summary of the rankings can be found in Table 5. A response of 1 indicated the most helpful module and a response of 5 indicated the least helpful module.

Table 5- Ranking of Modules in Terms of Helping to Improve Audit Skills

\begin{tabular}{|l|c|c|c|c|c|}
\hline \multirow{2}{*}{ Module } & \multicolumn{5}{c|}{ Ranking } \\
\cline { 2 - 6 } & $\mathbf{1}$ & $\mathbf{2}$ & $\mathbf{3}$ & $\mathbf{4}$ & $\mathbf{5}$ \\
\hline Planning & 4 & 7 & 4 & 2 & 1 \\
\hline Accounts Receivable & 5 & 6 & 7 & 8 & 1 \\
\hline Accounts Payable & 3 & 4 & 4 & 7 & 2 \\
\hline Fixed Assets & 2 & 2 & 6 & 3 & 7 \\
\hline Inventory & 7 & 2 & 3 & & 6 \\
\hline
\end{tabular}

In the final rank order type question, students were asked to rank order the Real Audit modules in terms of helping them to understand auditing. A response of 1 represented the most helpful module and a response of 5 represented the least helpful module. A summary of the rankings for understanding auditing can be found in Table 6. The summary indicates that students found the Planning and Accounts Receivable modules to be the most helpful and found the Fixed Assets and Inventory modules to be the least helpful. This result is consistent with the finding of the rank order type question on student interest.

Table 6- Ranking of the Modules in Terms of Helping to Understand Auditing

\begin{tabular}{|l|c|c|c|c|c|}
\hline \multirow{2}{*}{ Module } & \multicolumn{5}{c|}{ Ranking } \\
\cline { 2 - 6 } & $\mathbf{1}$ & $\mathbf{2}$ & $\mathbf{3}$ & $\mathbf{4}$ & 3 \\
\hline Planning & 6 & 6 & 2 & 4 & 4 \\
\hline Accounts Receivable & 5 & 7 & 4 & 4 & 1 \\
\hline Accounts Payable & 2 & 4 & 7 & 7 & 4 \\
\hline Fixed Assets & 2 & 3 & 3 & 3 & 6 \\
\hline Inventory & 6 & 1 & 5 & 6 \\
\hline
\end{tabular}

When asked which module offered the best learning experience, Accounts Receivable was selected by eight participants (36\%). When asked which module was the weakest in terms of learning experience, half of the participants, eleven, selected Fixed Assets. The participant responses to these two summary questions are consistent with the findings from the rank order type questions.

The students were next asked three open-ended questions. The first was "What did you like most about the project?" Some responses to the question were: the project provided hands-on experience, the project was different from a lecture, the project helped to apply auditing knowledge to real life examples, the project involved interaction with the client, the project allowed one to see the big picture, and the project allowed one to see how all of the pieces of an audit fit together. The second question was "What did you like least about the project?" The responses from 
students included: the project was too time consuming, the project did not afford enough guidance from the simulation product or the instructor, the project was difficult, the product's interface was not the best, the grading of the project was too harsh, and Real Audit's scoring system seemed to be inconsistent . The last question was "What suggestions do you have for improving the project?" The students suggested that more class time be devoted to the project in order to provide more guidance and allow time for questions, fewer modules should be assigned, the simulation product should allow data to be downloaded so that it can be further analyzed, the project should be done in groups, the grading should be easier, the project should have more structure, more hints should be given and more feedback should be provided.

The last question that the students responded to was a seven point Likert-scale type question that asked "Overall, how would you rate the quality of this project?" A response of one indicated that the quality was very poor and a response of seven indicated that the quality was excellent. The mean value was 4.25 with nine students responding with a 4 and eight students responding with a 5 or 6.

The responses of students to the survey questions seem to be consistent with the results from prior surveys. Students tend to think that the simulation increases their knowledge base and allows them to apply textbook knowledge to a real world activity. On the downside, students do not appreciate the ambiguous nature of simulations and would prefer more structure. Students also feel that the time commitment for simulations is too great. Overall, most students tend to feel that the simulation was a good educational experience and should be continued in future classes.

\section{REFERENCES}

1. Arner, B. (1998). One Teacher's Perspective: Simulation in the Classroom. Science Activities , 35 (1), 3-4.

2. Chen, W., \& Levinson, D. (2006). Effectiveness of Learning Transportation Network Growth through Simulation. Journal of Professional Issues in Engineering Education and Practice , 132 (1), 29-41.

3. Dori, Y., \& Belcher, J. (2005). How Does Technology-Enabled Active Learning Affect Undergraduate Student's Understanding of Electromagnetism Concepts? The Journal of the Learning Sciences , 14 (2), 243-279.

4. $\quad$ Drew, D. R. (1968). Traffic Flow Theory and Control. New York City: McGraw-Hill.

5. Gelinas, U., Schwarzkopf, D., \& Tibodeau, J. (2008). Introducing Students to the Integrated Audit with "Auditing Alchemy, Inc.". Journal of Information Systems , 22 (2), 151-170.

6. Nieschwietz, R., Pany, K., \& Zhang, J. (2002, Autumn). Auditing with Technology: Using Generalized Audit Software in the Classroom. Journal of Accounting Education, 307-329.

7. Porter, T., Riley, T., \& Ruffer, R. (2004). A Review of the Use of Simulations in Teaching Economics. Social Science Computer Review , 22 (4), 426-443.

8. Prisk, D., \& Dunn, N. (2002). Using Computer-Mediated Simulation to Improve Institutional DecisionMaking. Internet and Higher Education, 5 (4), 353-362.

9. Schatzel, J. (2008). Real Audit Instructor's Manual.

10. Schatzel, J. (2008). Real Audit Users Manual.

11. Spinello, E., \& Fischbach, R. (2008). Using a Web-Based Simulation as a Problem-Based Learning Experience: Perceived and Actual Performance of Undergraduate Public Health Students. Public Health Reports , 123 (52), 78-84.

12. Vescoukis, V., Retalis, S., \& Anagnostopoulos, D. (2003). Network-Based Business Simulation Activities in Technical Professional Education. Interactive Learning Environments , 11 (3), 169-191.

13. Weidenmier, M., \& Herron, T. (2004). Selecting an Audit Software Package for Classroom Use. Journal of Information Systems , 18 (1), 95-110.

14. Zeng, A., \& Johnson, S. (2009). Integrating a Discovery-based Laboratory to Teach Supply Change Management Fundamentals in an Undergraduate Management Course. Innovations in Education and Teaching International , 46 (1), 71-82. 